\title{
The embodied and relational nature of the mind: implications for clinical interventions in aging individuals and populations
}

This article was published in the following Dove Press journal:

Clinical Interventions in Aging

5 June 2013

Number of times this article has been viewed

\author{
W Jack Rejeski' \\ Lise Gauvin² \\ 'Department of Health and Exercise \\ Science and Department of Geriatric \\ Medicine, Wake Forest University, \\ Winston-Salem, NC, USA; ${ }^{2}$ Research \\ Center of the University of Montréal \\ Hospital Center, Department of Social \\ and Preventive Medicine, Université \\ de Montréal, Montréal, QC, Canada
}

Correspondence: W Jack Rejeski Wake Forest University, Departments of HES and Geriatric Medicine, Box 7868, Winston-Salem, NC 27109, USA

Email rejeski@wfu.edu

\begin{abstract}
Considerable research over the past decade has garnered support for the notion that the mind is both embodied and relational. Jointly, these terms imply that the brain, physical attributes of the self, and features of our interpersonal relationships and of the environments in which we live jointly regulate energy and information flow; they codetermine how we think, feel, and behave both individually and collectively. In addition to direct experience, evidence supports the view that stimuli embedded within past memories trigger multimodal simulations throughout the body and brain to literally recreate lived experience. In this paper, we review empirical support for the concept of an embodied and relational mind and then reflect on the implications of this perspective for clinical interventions in aging individuals and populations. Data suggest that environmental influences literally "get under the skin" with aging; that musculoskeletal and visceral sensations become more prominent in activities of the mind due to aging biological systems and chronic disease. We argue that conceiving the mind as embodied and relational will grow scientific inquiry in aging, transform how we think about the self-system and well-being, and lead us to rethink health promotion interventions aimed at aging individuals and populations.
\end{abstract}

Keywords: behavior change, gerontology, disablement, well-being, embodiment

\section{Introduction}

There is growing dissatisfaction with traditional conceptualizations of the mind as simply an emergent property of symbolic computations performed in the brain. This discontent has led to the development of broader, system-wide thinking in which the mind is viewed as embodied. ${ }^{1}$ Whereas the concept of an embodied mind emphasizes that the body helps to shape the way we think, feel, and behave, ${ }^{2}$ it is also important to acknowledge that the mind is relational. As one neuroscientist commented, "The individual neuron or a single human brain does not exist in nature. Without mutually stimulating interactions, people and neurons wither and die. In neurons this process is called apoptosis; in humans it is called depression, grief and suicide." In addition, whereas social synapses are as much a part of the mind as neuronal synapses, we will argue that an added dimension to the relational nature of the mind is the way in which the human body is highly integrated with the physical environment. This holistic worldview of humans, one that espouses mutual causation between the brain, body, and environment (social and physical) is consistent with complexity theory which has revolutionized thinking in physics, chemistry, biology, and even organizational psychology. ${ }^{4}$ Thus, in this paper, we employ a slightly modified version of Siegel's ${ }^{5}$ definition of "mind". He originally defined the mind as an embodied and relational 
process that regulates energy and information flow. In our modified version, the term relational captures not only energy and information flow that exists between people (the social environment), as suggested by Siegel, but also the interdependence that exists between people and their physical environments.

Although the nature of the mind is an intriguing theoretical issue, is it relevant to applied aging research, clinical practice, and public health? Does it really make a difference in the way that we care for, interact with, and support people as they age? We intend to illustrate that the perspective of an embodied and relational mind is critically important to the design of clinical interventions in aging; that, as people age, they benefit from changing the way in which they relate to and come to think about their own minds. Finally, we will illustrate why an embodied and relational mind reinforces the relevance of social interactions, movement, and mindfulness in health promotion with aging populations.

\section{Evidence for embodiment and the relational nature of mind}

In the field of cognitive science, Zalta and colleagues ${ }^{6}$ have stated that "In general, dominant views in the philosophy of mind and cognitive science have considered the body as peripheral to understanding the nature of mind and cognition. Proponents of embodied cognitive science view this as a serious mistake." In fact, the emergence of laboratories that study robotics led to the realization that interactions between the human body and the physical environment were central to understanding intelligence; it was not long before modeling in robotics became a distributed process including brain, body, and environment. ${ }^{7}$

Not all cognition need be embodied or relational as is true with mind-wandering, imagery, and planning. Yet, even these "offline" cognitive activities are enriched by embodiment, since stimuli embedded within past memories trigger multimodal simulations throughout the body and brain and recreate lived experience. ${ }^{8}$ In fact, bodily states likely become more central to the mind with aging. There are several reasons for this shift. First, with aging comes an increased salience of visceral influences on the brain and behavior. This is due to the increased prevalence of chronic disease in aging and related physical symptoms such as pain and fatigue. In a recent review, Critchley and Harrison ${ }^{9}$ provide a compelling argument for the way in which both activity in the brain and overt behavior are deter- mined by embodied visceral influences. Second, with aging there is a decline in sensory and motor function that changes the way people relate to the world around them. These impairments are often reflected in limitations with performing normal daily activities. And third, people observe changes in their bodies with aging, consequences that profoundly influence how they think, feel, and behave.

The role of bodily states and evidence for simulations in social cognition and behavior is well documented. ${ }^{10}$ For example, merely activating elderly stereotypes leads people to slow their gait. ${ }^{11}$ Not long ago, we conducted a longitudinal study of an aging cohort with knee pain and identified two subgroups at baseline that had impairments in leg strength, yet had either high or low self-efficacy for stair climbing. ${ }^{12}$ Thirty-months later, deficits in stair climb performance among those with low strength and low self-efficacy was dramatically greater than those with low strength and high self-efficacy. Notwithstanding what is known from Social Cognitive Theory, why do similar functional deficits or body states become coupled with such different perceived limitations? As the concept of an embodied and relational mind suggests, have older adults with high self-efficacy somehow compensated for impaired strength in a way that modifies the multi-sensory representation of their lived experience? Do they engage in activities and relationships that strengthen the embodied and relational nature of their minds?

The notion that the brain, body, and environment are codependent is not new. ${ }^{13}$ Recent neuroimaging studies show that when participants lay quiet in an fMRI scanner, simply viewing objects that are typically manipulated by the hands activates "grasping circuits" 14 and visualization of favorite foods increases connectivity in the sensorimotor networks and cerebellum, regions in the brain known to be active in the pursuit of food. ${ }^{15}$ Locatelli and colleagues ${ }^{16}$ found that the manual training of fine motor skills improved performance on semantically related action sentences and brain lesion studies show that categorical knowledge is impaired with damage to modality-specific systems. ${ }^{17}$

Evidence on emotion and affect further supports the concept of an embodied and relational mind. Research has shown that positive feelings induced with good news are enhanced by an upright or working posture and inhibited by a slumped posture ${ }^{18}$ and that humor in cartoons can be either facilitated or inhibited through manipulation of facial muscles used in smiling. ${ }^{19}$ In a recent brain imaging 
study, participants mimicked angry facial expressions from photographs under two conditions: a Botulinum Toxin (BOTOX) injection to block expressions of anger and one with no injection (control). ${ }^{20}$ Those receiving BOTOX had less activation in the limbic system of the brain compared to the control group.

The body also appears to be tightly linked to environmental stimuli in the experience of emotion. Harrison and colleagues ${ }^{21}$ simultaneously studied patterns of peripheral physiology and brain activity during two different forms of disgust: body-boundary-violation (BBV), responses to stimuli such as surgical videos, and core disgust (CD) that occurs when smelling rancid food or observing acts such as vomiting. Participants viewed videos of $\mathrm{BBV}$ and $\mathrm{CD}$ during which their brains were scanned and peripheral physiological data were recorded from the heart and gut. BBV induced notable shifts in the cardiovascular system, feelings of lightheadedness, and increased activity in the superior parietal region of the brain whereas CD induced feelings of nausea, an increase in dysregulated gastric responses, and greater activity in the ventral insula.

In summary, based on Siegel's ${ }^{5}$ definition of the mind, we underscore that the mind is dynamic and reflects reciprocal causation between brain, body, and environment. The terms embodied and relational imply that the brain, physical attributes of the self, and features of our interpersonal relationships and of the environments in which we live, jointly regulate energy and information flow and codetermine how we think, feel, and behave both individually and collectively.

\section{Implications for aging \\ The aging mind as embodied}

No one in aging research would question the important role that physical impairments have on the process of disablement in aging, yet oddly little attention has been given to the role that sensory information associated with the musculoskeletal system and the viscera play in understanding thoughts, feelings, and behavior as people age. In essence, the body and mind are often treated as being independent or that the body affects the mind because of the abstract meaning that the brain attributes to cues coming from it. However, evidence clearly points to the fact that the mind is embodied, a concept that neuroscientists acknowledge within the realm of "sickness behavior." Specifically, when infection invades the body, mobilized immune cells release cytokines that activate vagal neurons which then evoke a stereotypic behavioral response including fever, fatigue, social isolation, and lack of interest in food. ${ }^{9}$

With aging individuals, shifts in thoughts, feelings, and behavior triggered by activity within the musculoskeletal system and internal organs are more often the rule than an exception. Take, as just two examples, the experience of pain and fatigue or the challenge of restricting food consumption. Pain and fatigue, two symptoms highly dependent upon the receptors throughout the body, are common in aging because they accompany chronic disease and acute illness/injury; they have dramatic effects on mobility and social engagement. The prevalence of pain in community dwelling older adults exceeds $70 \%{ }^{22}$ and fatigue is reported as a barrier in daily life by $31.2 \%$ of people aged 51 and older; fatigue is higher among minorities than whites (in a large US population including African-Americans and Hispanics), 47.5\% vs $27.5 \%$ and, as with pain interference, there is a positive slope with aging. ${ }^{23}$

The desire to consume food is also embodied and becoming increasing important as a topic in aging. Obesity is an epidemic across the lifespan with prevalence rates for adults aged $65-74$ in the US reported to be $40.8 \% .^{24}$ In addition to the chronic disease burden of obesity, it is a major risk factor for physical disability. ${ }^{25}$ Studying adults aged $>60$ we are investigating a visceral cue hypothesis that food cues in the environment alter brain networks and may be a source of self-regulatory failure within dietary interventions. It is based on a concept termed the "cold to hot empathy gap." 26 Applied to eating behavior, "cold states" lead people to overestimate their ability to control food consumption; for example, after they have just eaten. By contrast, during "hot states" these beliefs fall apart; for example, peoples' desire to consume food changes within 2-3 hours after having eaten.

To test this hypothesis, we had older, obese participants come to our laboratory on two different occasions. Each visit began early in the morning with consumption of a controlled breakfast after which they did not eat for 2.5 hours. On one visit, they consumed only water following food restriction ("hot state"); on a second visit they consumed a liquid meal replacement ("cold state"). Following the feeding manipulations, brain scans were conducted in which participants imaged their favorite foods and then rested for 5 minutes in the scanner so that we could evaluate recovery brain networks. The findings were striking in that cravings were substantially higher and control for eating desired foods dramatically lower when participants were in a "hot" versus a "cold" state. ${ }^{15}$ Most important, we observed marked shifts 
in brain networks between the two conditions, suggesting that visceral cues from restraint had primed addictive-like networks in the brain.

These findings underscore the importance of serial assessments with a variety of environmental exposures when attempting to understand self-regulatory behavior in aging. The data also suggest that interventions should work with people during periods of vulnerability and actively teach coping strategies to deal with motivational shifts that occur in conjunction with the dynamic nature of the mind.

\section{Vagal tone: evidence that the mind spans from brain, to body, to environment}

From an evolutionary perspective, the human nervous system evolved to protect us against threat, both internal and external. It is the nervous system that plays a central role in regulating energy and information flow between the brain, body, and environment; it is a core system in understanding the embodied and relational nature of the mind. Porges ${ }^{27}$ has made a compelling argument for the position that cardiac vagal tone, measured as respiratory sinus arrhythmia (RSA), represents a continuous, unconscious biomarker of such threat, a process that he terms Neuroception. Early attachment and feelings of isolation have a major effect on both the development of and modifications to this system as can trauma. ${ }^{27}$

Because vagal tone is a biomarker of threat and, hence stress, Thayer and colleagues ${ }^{28}$ have argued that it is an index for self-regulatory capacity affecting such diverse outcomes as homeostasis, emotional regulation, executive cognitive function, and overt behavior. Stress has a logical relationship to conscious self-regulatory capacities since it downregulates activity in the prefrontal cortex, which is the hub for executive cognitive processes. Internal threats common to aging include such experiences as the burden of chronic disease, deficits with mobility, and decline in cognitive function; external threats emerge from compromised physical and sensory capacities, decreased social interactions, and environments that are not user-friendly. The take home message is that these threats in aging compromise vagal tone and are likely implicated in self-regulatory failure.

\section{More on the relational mind}

A new science of learning ${ }^{29}$ has developed in parallel with key assumptions of an embodied and relational mind; this perspective has critical implications for aging since behavior change often involves learning. This approach promotes learning as a social process supported by brain networks which link perception and action. In other words, the observation and imitation of others is a powerful mode of implicit learning not because people can abstract in their brains what others are doing; rather, humans actually replicate the brain-body networks modeled by others.

With the emphasis on knowledge that has emerged from interpersonal neurobiology and the group dynamics literature, we recently developed and tested the efficacy of a group-mediated weight loss intervention for sedentary, obese adults in conjunction with community partnerships to counter physical disablement in aging. This mindfulness-based approach to behavior change focuses on caloric restriction and increases in physical activity using existing community infrastructures; it uses the group and social learning as a means of developing goals, motives, skills, and strategies to facilitate target behaviors. Data have now shown that this approach leads to improved mobility ${ }^{30}$ and that the effect is mediated by an increase in self-confidence that participants acquired from the intervention. ${ }^{31}$

At this point, a reasonable question to ask is what learning as a social process ${ }^{29}$ has to do with mindfulness. We begin by emphasizing that the term mindfulness is most commonly associated with the practice of meditation. It represents a quality of consciousness that differs substantially from conceptual thinking that we use to plan, problem-solve, and accomplish tasks in day-to-day living. According to Keng, ${ }^{32}$ mindfulness is "awareness of one's moment-to-moment experience, nonjudgmentally and with acceptance.” Although this definition is succinct and clearly stated, an often overlooked fact is that mindfulness is foremost an embodied and relational experience and that it can be facilitated by means other than meditation. Thus, consistent with Meltzoff and colleagues, ${ }^{29}$ learning as a social process only occurs when people connect with and process the energy and information flow emanating from others as they communicate their experiences to the group. Employing group-mediated approaches to behavior change, interventionists are trained to facilitate and coregulate these interpersonal exchanges and thus facilitate mindfulness.

Also of interest is the manner in which the environment and the promotion of physical activity behavior appear to facilitate social interactions and thus social learning in individuals and perhaps populations. Specifically, older adults living in areas with more resources and amenities engage in more bouts of walking and are more likely to participate in a higher frequency of and more varied social activities. ${ }^{33,34}$ In keeping with the idea that an embodied and relational mind is important for populations as well as individuals, we 
draw from epidemiology the notion that health status later in life is, in part, a reflection of the accumulated embodiment of social circumstances across the lifespan. ${ }^{35,36}$ For example, Glymour and Manly ${ }^{37}$ show that between population differences in cognitive function with aging can be explained by environmental disadvantages including discrimination, stereotypes, limited group resources, and the absence of social ties. In other words, physical and social environments literally "get under the skin" in entire populations. ${ }^{38}$

\section{Treatment from the outside-in and bottom-up}

When changing behavior at the individual or population level and whether targeting physical or emotional health, an important lesson is that the task is best accomplished when Neuroception generates feelings of safety. The reason is that feelings of being safe promote cognitive flexibility ${ }^{39}$ and inhibit dominant impulsive emotional reactions to life events. ${ }^{40}$ People with higher vagal tone are able to selfregulate negative facial expressions ${ }^{41}$ and report a lower frequency of adverse responses to environmental stressors ${ }^{42}$ as compared to those with low vagal tone.

Data from a recent prospective study using experience sampling showed that higher initial baseline vagal tone was positively related to reports of greater social connectedness and positive emotions throughout the day and that social connectedness and positive emotions were predictive of increases in vagal tone independent of baseline levels. ${ }^{43}$ Also relevant is the value inherent in creating environmental buoys to facilitate action among people with physical impairments. ${ }^{44}$ What becomes clear is that in addition to research on promoting social engagement in aging, there is a need to develop strategies that inculcate the value of such experiences as people age so that social connectedness becomes an essential part of the self-system and collective functioning. This research direction would embrace the relational nature of mind and emphasize the importance of interventions that function from the outside-in.

There also has been a long history of theoretical interest in generativity, the concern for and activity directed at the well-being of others, which has been linked to improved cognitive and physical well-being in aging. ${ }^{45}$ In fact, a recent study using a large national sample showed that higher levels of generativity were longitudinally related to lower odds of worsening ADL disability and mortality. ${ }^{46}$ Creating the opportunity for generativity can be realized in populationbased interventions through health promotion activities that elicit and strengthen social ties and promote prosocial behavior.

In keeping with an embodied view of mind, fostering feelings of safety at the individual level would best begin from the bottom-up rather than top-down; that is, to intervene on brain networks that promote safety and create reception attention, focus on the body first and thought second. Essential skills for creating feelings of safety which facilitate openness include the relaxation response and mindfulness. Alan Fogel $^{47}$ has argued that being mindfully aware of our embodied nature is fundamental to survival; that "... the loss of embodied self-referent awareness at any time in the life course is debilitating" both physically and psychologically. He posits that embodied self-awareness is instrumental to maintaining physiological homeostasis, a point supported by the work of Thayer and Colleagues, ${ }^{28}$ that it enables the conceptual self to exist in an integrated manner with our embodied and relational self. Previous work of ours suggests that body-related interventions such as physical activity can provide an ideal medium for helping older adults to reconnect with their bodies. ${ }^{48}$ Unfortunately, the increased prevalence of disease and disability with aging creates further distance from, rather than encouraging people to embrace embodied self-awareness. This conundrum suggests that mindfulness and other body-related interventions are prime areas for future studies in aging. ${ }^{47}$

Additionally, as Benson and Proctor ${ }^{49}$ have suggested, imagery may have healing potential when combined with the relaxation response. Consistent with Barsalou, ${ }^{8}$ mental imagery is but one example of the creative power of an embodied mind to recreate or simulate past experience. If older adults could be taught to use imagery in a systematic manner to activate the multisensory experience of healthy states, it seems plausible that they could activate positive biological effects on the nervous, endocrine, and immune systems. Interestingly, recent population-based interventions aimed at built environments in urban areas have been directed at increasing safety through structural changes (eg, crime reduction, traffic calming ${ }^{43}$ ). An examination of the impact that environmental interventions have on biomarkers such as vagal tone would appear to be a fruitful undertaking.

\section{Embodiment and relational movement: promoting mindfulness in aging}

Reframing the mind as an embodied and relational process should encourage investigators to rethink the structure and importance of movement-based interventions in aging. 5,50 As we will illustrate below, these interventions can tune 
body structures and awareness and promote well-being. Currently, the major focus of funding agencies, professional organizations, and federal initiatives is on walking or aerobic exercise. Although there is enormous clinical and public health wisdom in the promotion of walking as people age, and there is substantial empirical support for its efficacy, the ideas promoted in this paper suggest that this focus is too narrow.

One obvious consequence of aging, due in part to the prevalence of sedentary behavior in our culture, is that people become physically deconditioned in the broadest sense of its meaning. Not only do muscular strength and cardiovascular conditioning decline, but there is a gradual loss of function in both the embodied and relational mind because proprioceptive sensitivity declines, ${ }^{51}$ the sense of hearing and vision suffer, ${ }^{52}$ and the clarity of body schema - the location, size, relation, and coordination of body parts in space - begins to fade or become distorted. ${ }^{51}$ Our hypothesis is that this series of events creates threat, leads to a lowering of RSA, and thus to a further loss of physical competence and the progression of physical disablement. Interestingly, Liu-Ambrose and colleagues $^{53}$ have shown that, compared to a stretching program, both resistance training and agility training in older women aged 75-85 lowered the risk for falling and that a potential mediator of this effect was decreased postural sway - an outcome that is highly dependent upon peripheral physiology such as proprioception.

Several years ago, we conducted a small pilot study in which we randomized older adults with a range of function to either a standard walking program for 6 weeks or to one that involved walking combined with intermittent stations that challenged balance, coordination, and a combination of movement and executive cognition function - walk.$+{ }^{54} \mathrm{By}$ virtue of the physical demands, participants had to consciously focus their awareness on coordinated movements and were fully absorbed in what they were attempting to accomplish. In essence, we had coerced them into a state of mindfulness in which their attention was devoted to an awareness of coordinated movement in space, an experience that tapped into body schema. After randomization, participants in both treatment conditions were classified as either low and high functioning based on a standard test of physical functioning. Results were striking in that baseline level of functioning interacted with treatment efficacy. That is, in terms of functional improvement, the high functioning participants benefitted most from the walking intervention whereas the low functioning group improved substantially more when exposed to the walk+ intervention. Although we cannot be certain about the cause of these differences due to both sample size and study design, our belief is that the low functioning participants had more to gain from the basic motor, walk+ intervention, whereas those higher in function were "better matched" to the demands of the walking program.

Similarly, a recent cluster-randomized trial aimed at changing cognitive function among older adults and involving either cycling on a stationary cycle ergometer in a sterile environment or in a virtual-reality enhanced environment (ie, viewing pleasant landscapes and scenery) illustrates the powerful contribution of environmental stimuli to cognitive health. ${ }^{55}$ Specifically, they showed that cycling in an enhanced environment led to greater improvements in cognitive function and lower likelihood of clinical progression to mild cognitive impairment over a period as short as 3 months. As mentioned above, the lesson to be learned here is that, as mobility declines, so too does kinesthetic awareness, dynamic balance, and the decision making that is typically integrated with perception and action. In essence, a disintegration of the embodied and relational sense of self that is tightly networked with activity in the brain can be a consequence of aging, an effect that leads to system wide functional deficits and decline in well-being.

We would like to close this section by emphasizing that the mind, like the very structure of muscle itself, needs to be trained to reach its full capacity. Across the lifespan, we have witnessed an increasing emphasis on "doing things", getting ahead, meeting the expectations thrust upon us by society, and of being completely absorbed in the conceptual self - what Mark Leary ${ }^{56}$ has labeled "The Curse of the Self." The consequence for many of us is that the embodied and relational dimensions of our minds are rarely attended to; they are underdeveloped. The embodied mind becomes conditioned by a society that rewards "getting ahead" and often requires that feelings are suppressed because they interfere with doing so. We are becoming further absorbed in technological advancements with each passing day: we text rather than talk, stay glued to our iPhones when on vacation or walking from one place to another, and run or walk for exercise with a stream of music whisking us away from any opportunity for an embodied or relational experience!

Whereas the toll of this lifestyle on our mental and physical health with aging continues to be documented, ${ }^{57}$ the take-home message from this paper is that research on aging should take seriously the potential inherent in mindfulbased activities that foster proprioceptive capacities and body schema. A good place to begin is with interventions that have proven efficacy or are highly promising including yoga, ${ }^{58}$ Tai-Chi, ${ }^{59}$ agility training, ${ }^{53}$ resistance training, ${ }^{53}$ and 
dance. ${ }^{60}$ One caveat, whereas Tai-Chi and some forms of yoga promote active engagement with body sensations, this is not the case for most physical activities promoted in Western culture. Consistent with Fogel, ${ }^{47}$ we would argue that it is being receptive to and fully absorbed in body sensations and the environment as we move that is therapeutic. This is not to suggest that the conceptual self is unimportant or that goals are irrelevant. However, cultivating mindfulness promotes integration that can inform the conceptual self and help to preserve well-being. ${ }^{47}$ Evidence from a variety of literatures support the value of mindfulness in the management of physical symptoms such as pain ${ }^{61}$ and in the promotion of both physical ${ }^{62}$ and mental health. ${ }^{32}$

\section{Therapeutic interventions, disease prevention, and health promotion}

Throughout this manuscript we have strived to illustrate how conceiving the mind as embodied and relational can transform the advancement of knowledge and the development of interventions aimed at treating or preventing disability and chronic health conditions in aging. However, we want to underscore the fact that this new paradigm may also serve to promote positive health and thriving. A recent book ${ }^{63}$ draws a portrait of 50 renowned individuals whose major life achievements occurred at age 50 or later: Fred Astaire made a very successful come back to the silver screen after he retired at age 50, Johan Sebastian Bach composed the Art of Fugue at 65, Sir Francis Chichester sailed around the world alone at 65, Nicolaus Copernicus described the solar system at age 62 , Claude Monet the French impressionist painter created Nymphéas at 76, Leonardo DaVinci painted the Mona Lisa at age 54, and JRR Tolkien wrote the Lord of the Rings at 62! Indeed the ideas conveyed in this paper are in keeping with research emerging from the positive psychology movement, ${ }^{64}$ a focal area of research with an interest in the neurobiology, emotions, and behavior associated with happiness/well-being and interventions that promote growth and flourishing. ${ }^{65,66}$ Conceiving the mind as embodied and relational dovetails nicely with the growing literature on successful aging ${ }^{67-70}$ and may serve to further strengthen the development of health promotion interventions in aging that would complement work on therapeutic and disease prevention.

\section{Conclusion}

There is strong empirical evidence from research on cognition and emotion that the mind is embodied and relational and not simply an emergent property of symbolic computations performed in the brain. Hence the brain, physical attributes of the self, and features of our interpersonal relationships and of the environments in which we live, jointly regulate energy and information flow; they codetermine how we think, feel, and behave both individually and collectively. This paradigmatic shift implies that social and physical environments literally "get under the skin" with aging; that bodily states become more prominent in the minds of an aging population. There is enormous value in being mindfully aware of our embodied and relational nature as we age; creating a life space that promotes feelings of safety and social connectedness, states that are conducive to openness, growth, and thriving. Because of the human capacity to simulate multi-sensory experience, there is every reason to believe that imagery around the theme of a healthy body and mind will have positive effects on biological and psychological systems with aging. The fundamental message is that conceiving the mind as embodied and relational will grow scientific inquiry in aging, transform how we think about the self-system and well-being, and lead us to rethink health promotion interventions aimed at aging individuals and populations.

\section{Acknowledgments}

Support for this work was provided by (a) National Heart, Lung and Blood Institute grant R18 HL076441 awarded to W Jack Rejeski and (b) a National Institutes for Aging grant P30 AG021332 on which W Jack Rejeski is a coinvestigator. Also, Lise Gauvin holds an Applied Public Health Chair on Neighborhoods, Lifestyle, and Healthy Body Weight which is supported by the Canadian Institutes of Health Research and the Centre de recherche en prévention de l'obésité.

\section{Disclosure}

The authors declare no conflicts of interest in this work.

\section{References}

1. Niedenthal PM, Barsalou LW, Winkielman P, Krauth-Gruber S, Ric F. Embodiment in attitudes, social perception, and emotion. Per Soc Psychol Rev. 2005;9(3):184-211.

2. Pfeifer R. The Body Shapes the Way We Think: A New View of Intelligence. Cambridge: MIT Press; 2007.

3. Cozolino L. The Neuroscience of Human Relationships. New York: WW Norton \& Co; 2006.

4. Dent EB. Complexity science: a worldview shift. Emergence. 1999; 1(4):5-19.

5. Siegel DJ. The Mindful Brain. New York: WW Norton \& Co; 2007

6. Zalta EN, Nodelman U, Allen C, Perry T. Embodied Cognition. Fall 2011 edition of the Standford Encyclopedia of Philosophy 2011; Available at: URL: http://plato.stanford.edu/archives/fall2011/entries/ embodied-cognition/.

7. Brooks RA. New approaches to robotics. Science. 1991;253(5025): $1227-1232$. 
8. Barsalou LW. Grounded cognition. Annu Rev Psychol. 2008;59: 617-645.

9. Critchley HD, Harrison NA. Visceral influences on brain and behavior. Neuron. 2013;77(4):624-638.

10. Decety J, Grezes J. The power of simulation: imagining one's own and other's behavior. Brain Res. 2006;1079(1):4-14.

11. Dijksterhuis A, Bargh JA. The perception-behavior expressway: automatic effects of social perception on social behavior. In: Zanna MP, editor. Advances in Experimental Social Psychology. San Diego, CA: Academic Press; 2001:1-40.

12. Rejeski WJ, Miller ME, Foy CG, Messier SP, Rapp S. Self-efficacy and the progression of functional limitations and self-reported disability in older adults with knee pain. J Gerontol B Psychol Sci Soc Sci. 2001;56B(5): S261-S265.

13. Wilson M. Six views of embodied cognition. Psychonomic Bull Rev. 2002;9(4):625-636.

14. Chao LL, Martin A. Memory in hand: grasping the concept of tools. J Cogn Neurosci. 2000;76.

15. Rejeski WJ, Burdette J, Burns M, et al. Power of food moderates food craving, perceived control, and brain networks following a short-term post-absorptive state in older adults. Appetite. 2012;58:806-813.

16. Locatelli M, Gatti R, Tettamanti M. Training of manual; actions improves language understanding of semantically related action sentences. Frontiers Psychol. 2012;3:1-10.

17. Humphreys GW, Forde EME. Hierarchies, similarity, and interactivity in object recognition: "Category-specific" neuropsychological deficits. Behav Brain Sci. 2001;24(3):453-476.

18. Stepper S, Strack F. Proprioceptive determinants of emotional and nonemotional feelings. J Per Soc Psychol. 1993;64(2):211-220.

19. Strack F, Martin LL, Stepper S. Inhibiting and facilitating conditions of the human smile - a nonobtrusive test of the facial feedback hypothesis. J Per Soc Psychol. 1988;54(5):768-777.

20. Hennenlotter A, Dresel C, Castrop F, Baumann AOC, Wohlschlager AM, Haslinger B. The Link between facial feedback and neural activity within central circuitries of emotion: new insights from botulinum toxin-induced denervation of frown muscles. Cereb Cortex. 2009;19(3): $537-542$.

21. Harrison NA, Gray MA, Gianaros PJ, Critchley HD. The embodiment of emotional feelings in the brain. $J$ Neurosci. 2010;30(38): $12878-12884$

22. Brody EM, Kleban MH. Day-to-day mental and physical health symptoms of older people: a report on health logs. Gerontologist. 1983;23(1):75-85.

23. Meng H, Hale L, Friedberg F. Prevalence and predictors of fatigue in middle-aged and older adults: evidence from the health and retirement study. J Am Geriatr Soc. 2010;58(10):2033-2034.

24. Fakhouri THI, Ogden CL, Carroll MD, Kit BK, Flegal KM. Prevalence of obesity among older adults in the United States, 2007-2010. NCHS Data Brif, No 106 2012; Available at: URL: http://www.cdc.gov/nchs/ data/databriefs/db106.htm.

25. Rejeski WJ, Marsh AP, Chmelo E, Rejeski JJ. Obesity, intentional weight loss and physical disability in older adults. Obes Rev. 2010;11(9): 671-685.

26. Loewenstein G. Out of control: visceral influences on behavior. Organ Behav Hum Decis Process. 1996;65(3):272-292.

27. Porges SW. The Polyvagal Theory, 1st ed. New York, NY: WW Norton \& Co, Inc; 2011.

28. Thayer JF, Hansen AL, Saus-Rose E, Johnsen BH. Heart rate variability, prefrontal neural function, and cognitive performance: the neurovisceral integration perspective on self-regulation, adaptation, and health. Ann Behav Med. 2009;37(2):141-153.

29. Meltzoff AN, Kuhl PK, Movellan J, Sejnowski TJ. Foundations for a New Science of Learning. Science. 2009;325(5938):284-288.

30. Rejeski W, Brubaker P, Goff D, et al. Translating weight loss and physical activity programs into the community to preserve mobility in older, obese adults in poor cardiovascular health. Arch Intern Med. 2011;17: $880-886$.
31. Brawley L, Rejeski WJ, Gaukstern JE, Ambrosius WT. Social cognitive changes following weight loss and physical activity interventions in obese, older adults in poor cardiovascular health. Ann Behav Med. 2012; 44(3):353-364.

32. Keng SL, Smoki MJ, Robins CS. Effects of mindfulness on psychological health: a review of empirical studies. Clin Psychol Rev. 2011;31:1041-1056.

33. Gauvin L, Richard L, Kestens Y, et al. Living in a well-serviced urban area is associated with maintenance of frequent walking among seniors in the VoisiNuAge study. J Gerontol: Soc Sci. 2012;67(1):76-88.

34. Richard L, Gauvin L, Kestens Y, et al. Neighborhood resources and social participation among older adults: results from the VoisiNuage study. J Aging Health. 2012;25(2):296-318.

35. Krieger N. Embodiment: a conceptual glossary for epidemiology. $J$ Epidemiol Community Health. 2005;59(5):350-355.

36. Kuh D, Ben Shlomo Y. A Life Course Approach to Chronic Disease Epidemiology, 2nd ed. New York: Oxford University Press; 2004.

37. Glymour MM, Manly JJ. Lifecourse social conditions and racial and ethnic patterns of cognitive aging. Neuropsychol Rev. 2008;18(3):223-254.

38. Taylor SE, Repetti RL, Seeman T. Health psychology: what is an unhealthy environment and how does it get under the skin? Annu Rev Psychol. 1997;48:411-447.

39. Hansen AL, Johnsen BH, Thayer JE. Vagal influence on working memory and attention. Int J Psychophysiol. 2003;48(3):263-274.

40. Johnsen BH, Thayer JF, Laberg JC, et al. Attentional and physiological characteristics of patients with dental anxiety. J Anxiety Disord. 2003; 17(1):75-87.

41. Demaree HA, Pu J, Robinson JL, Schmeichel BJ, Everhart ED. Predicting facial valence to negative stimuli from resting RSA: not a function of active emotion regulation. Cog Emot. 2006;20(2):161-176.

42. El-Sheikh M, Harger J, Whitson SM. Exposure to interparental conflict and children's adjustment and physical health: the moderating role of vagal tone. Child Dev. 2001;72(6):1617-1636.

43. Kok BE, Fredrickson BL. Upward spirals of the heart: autonomic flexibility, as indexed by vagal tone, reciprocally and prospectively predicts positive emotions and social connectedness. Biol Psychol. 2010;85(3):432-436.

44. Glass TA, Balfour JL. Neighborhoods, aging, and functional limitations. In: Kawachi I, Berkman LF, editors. Neighborhoods and Health. Oxford: Oxford University Press; 2003:303-334.

45. Adams KB, Leibbrandt S, Moon H. A critical review of the literature on social and leisure activity and wellbeing in later life. Ageing Soc. 2011;31:683-712.

46. Gruenewald TL, Liao DH, Seeman TE. Contributing to others, contributing to oneself: perceptions of generativity and health in late life. J Generontol: Psychol Sci. 2012;67B(6):660-666.

47. Fogel A. The Psychophysiology of Self-Awareness. New York: WW Norton \& Co, 2009

48. Rejeski WJ. Reconnecting the body and mind in Geriatric Medicine and Gerontology. Gerontologist. 2008;48(2):135-141.

49. Benson H, Proctor W. Relaxation Revolution. New York: Scribner; 2010.

50. Sporns O. Networks of the Brain. Cambridge, MA: MIT Press; 2011.

51. Shaffer SW, Harrison AL. Aging of the somatosensory system: a translational perspective. Physical Therapy. 2007;87:193-207.

52. Lord SR, Menz HB. Visual contributions to postural stability in older adults. Gerontology. 2000;46:306-310.

53. Liu-Ambrose T, Khan KM, Eng JJ, Jansen SR, Lord SR, McKay HA. Resistance and agility training reduce fall risk in women aged 75-85. JAGS. 2004;52:657-665.

54. Marsh AP, Chmelo EA, Katula JA, Mihalko SL, Rejeski WJ. Should physical activity programs be tailored when older adults have compromised function? J Aging Phys Act. 2009;17(3):294-306.

55. Anderson-Hanley C, Arciero PJ, Brickman AM, et al. Exergaming and older adult cognition: a cluster randomized clinical trial. Am J Prev Med. 2012;42(2):109-119.

56. Leary MR. The Curse of the Self: Self-Awarness, Egotism, and the Quality of Human Life. New York: Oxford Press, 2007. 
57. McEwen BS, Gianaros PJ. Stress and allostasis-induced brain plasticity. Annu Rev Med. 2011;62:431-445.

58. Patel NK, Newstead AH, Ferrer FL. The effects of yoga on physical function and health-related quality of life in older adults: a systematic review and meta-analysis. J Altern Compl Med. 2012;18:902-917.

59. Adler PA, Roberts BL. The use of Tai Chi to improve health in older adults. Orthop Nurs. 2006;25:122-126.

60. Keogh JWL, Kilding A, Pidgeon P, Ashley L, Gillis D. Physical benefits of dancing for healthy older adults: a review. J Aging Phys Act. 2009;17:1-23.

61. Ford D, Thompson M. Relaxation and mindfulness in pain: a review. Rev Pain. 2012;4:18-22.

62. Grossman P, Niemann L, Schmidt S, Walach H. Mindfulness-based stress reduction and health benefits: a meta-analysis. J Psychosom Res. 2004;57:35-43.

63. Dudan E. 50 ans et après?!: La réponse en 50 portraits ( 50 years and after?!: The answer in 50 portraits). Italy: Timée-Éditions.

64. Seligman ME, Csikszentmihalyi M. Positive psychology: an introduction. Am Psychol. 2000;55(1):5-14.
65. Aspinwall LG, Tedeschi RG. The value of positive psychology for health psychology: progress and pitfalls in examining the relation of positive phenomena to health. Ann Beh Med. 2010;39(1):4-15.

66. Kobau R, Seligman ME, Peterson C, et al. Mental health promotion in public health: perspectives and strategies from positive psychology. Am J Public Health. 2011;101(8):e1-e9.

67. Rowe JW, Kahn RL. "Successful Aging". The Gerontologist. 1997; 37(4):433-440.

68. Kraft E. Cognitive function, physical activity, and aging: possible biological links and implications for multimodal interventions. Aging Neuropsychol Cognition. 2012;19(1-2):248-263.

69. Eyler LT, Sherzai A, Kaup AR, Jeste DV. A review f functional brain imaging correlates of successful cognitive aging. Biol Psychiatry. 2011; 70(2):115-122.

70. Depp C, Vahia IV, Jeste D. Successful aging : focus on cognitive and emotional health. Ann Rev Clin Psychol. 2010;6:527-550.
Clinical Interventions in Aging

\section{Publish your work in this journal}

Clinical Interventions in Aging is an international, peer-reviewed journal focusing on evidence-based reports on the value or lack thereof of treatments intended to prevent or delay the onset of maladaptive correlates of aging in human beings. This journal is indexed on PubMed Central, MedLine, the American Chemical Society's 'Chemical Abstracts Ser-

\section{Dovepress}

vice' (CAS), Scopus and the Elsevier Bibliographic databases. The manuscript management system is completely online and includes a very quick and fair peer-review system, which is all easy to use. Visit http://www.dovepress.com/testimonials.php to read real quotes from published authors. 